\title{
Extensão da vida de prateleira de ovos pela cobertura com própolis
}

\section{Increased shelf life of eggs through the use of propolis}

\author{
José Xavier de Carvalho ${ }^{1 *}$; Rafael Ojeda Suárez²; Fabrícia Queiroz Mendes ${ }^{3}$; \\ Regiane Victória de Barros Fernandes ${ }^{4}$; Marília Crivelari da Cunha ${ }^{5}$; \\ André Mundstock Xavier de Carvalho ${ }^{6}$
}

\section{Resumo}

Devido a sua facilidade de obtenção, manejo, preço e valor biológico, o ovo é um dos alimentos mais consumidos no mundo. No entanto, por ser basicamente utilizado in natura, oferece riscos quando alguns cuidados não são observados em seu manuseio, armazenamento e prazo de validade. O objetivo deste trabalho foi estender o período de validade dos ovos através do uso de própolis de abelhas (Apis mellifera). Os ovos foram cobertos com uma película de própolis e comparados com ovos não lavados e lavados. Foram avaliadas a perda de massa, massa específica, unidade Haugh, altura da câmara de ar e a presença de bactérias dos grupos coliformes totais, termotolerantes e do gênero Salmonella. A cobertura com própolis promoveu menor perda de massa, menor redução da massa específica, menor perda da unidade Haugh com manutenção do tamanho da câmara de ar. Coliformes ou bactérias do gênero Salmonella não foram encontrados em ovos revestidos com própolis. Assim, observou-se que a cobertura de ovos com própolis mantém as qualidades internas e microbiológicas por mais tempo, aumentando a vida de prateleira dos mesmos.

Palavras-chave: Unidade Haugh, Gallus domesticus, Apis mellifera, atividade antimicrobiana

\begin{abstract}
Due to its ease of obtaining, handling, price and biological value, the egg is one of the most consumed foods in the world. However, because it is basically for in natura use, offers risks when care is not observed on its handling, storage and shelf life. The objective of this research was to increase the shelf life of hens eggs (Gallus domesticus) using the bee propolis (Apis mellifera). Eggs were covered with a film of propolis and these eggs were compared with uncovered ones: unwashed and washed eggs. Weight loss, density, Haugh unit, height of the air chamber and survey of total coliform, coliform and Salmonella were evaluated. The coverage with propolis provided less weight loss, lower reduction of density and loss of the Haugh unit. The process also allow to kept the size of the air chamber. No coliforms or Salmonella were found in eggs coated with propolis. Thus, it was observed that the coverage of eggs with propolis increases the shelf life and maintains internal and microbiological qualities of the eggs.
\end{abstract}

Key words: Haugh units, Gallus domesticus, Apis mellifera, antimicrobial activity

\footnotetext{
${ }^{1}$ Discente de Mestrado em Agroecología y Agricultura Sostenible, Universidad Agraria de La Habana "Fructuoso Rodríguez Pérez", UNAH, San José de las Lajas, La Habana, Cuba. E-mail: jxavierdecarvalho@yahoo.com.br

${ }^{2}$ Prof. da UNAH, San José de las Lajas, La Habana, Cuba. E-mail: rafael.ojeda@infomed.sld.cu

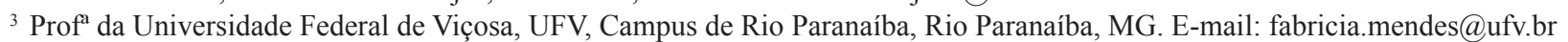

${ }^{4}$ Técnica, UFV, Campus de Rio Paranaíba, Rio Paranaíba, MG. E-mail: regi_ufv@yahoo.com.br

${ }^{5}$ Discente, UFV, Campus de Rio Paranaíba, Rio Paranaíba, MG. E-mail: mari_crivelari@yahoo.com.br

${ }^{6}$ Prof. da UFV, Campus de Rio Paranaíba, Rio Paranaíba, MG. E-mail: andre.carvalho@ufv.br

* Autor para correspondência
} 


\section{Introdução}

O ovo de galinha (Gallus domesticus) é um dos produtos de grande aporte proteico/calórico e vitamínico, de baixo preço e fácil produção. $\mathrm{O}$ aumento do consumo de ovos e a utilização de suas vantagens nutricionais pela população dependem da qualidade do produto oferecido ao consumidor. $\mathrm{O}$ ovo começa a perder sua qualidade interna logo após a postura, caso não sejam tomadas medidas adequadas para sua conservação. A perda de qualidade é um processo inevitável e contínuo ao longo do tempo, mas que pode ser agravado por diversos fatores, alguns deles controláveis durante a pós-colheita (BARBOSA et al., 2008).

O prazo de validade em pós-colheita de ovos é curto, o que desencadeia uma série de dificuldades na logística de comercialização. A utilização de tecnologias para preservar a qualidade interna de ovos como, a imersão em óleo mineral ou a adição de coberturas tem sido objeto de estudos, visto que normalmente os ovos têm sido comercializados in natura e sem refrigeração (SILVA et al.; 2010a; WAIMALEONGORA-EK et al., 2009; CANER, 2005; BHALE et al., 2003; WONG; HERALDS; HACHMEISTER, 1996).

Em termos tecnológicos, a produção sofreu grande evolução, indo desde a especialização de raças poedeiras de alta definição zootécnica, melhoria da nutrição, dos padrões das instalações e o desenvolvimento de ovos com valores nutraceuticos adicionais, como a incorporação de ômega 3 e vitamina E. Todavia, por ser um produto basicamente de uso in natura, o ovo pode oferecer riscos à saúde humana quando não observados alguns cuidados necessários às etapas de produção e manuseio pós-colheita.

A redução da qualidade interna dos ovos está associada principalmente à perda de água e de dióxido de carbono durante o período de estocagem e é proporcional à elevação da temperatura do ambiente (AUSTIC; NESHEIM, 1990). Essa troca gasosa resulta em alteração do $\mathrm{pH}$ da clara, com consequente alteração das proteínas e propriedades funcionais, além da perda de massa.

Selecionar critérios para avaliar a qualidade de ovos implica em considerar a qualidade sob diferentes perspectivas. Para os produtores, a qualidade está relacionada à massa dos ovos e à resistência da casca. Para os consumidores, a qualidade está relacionada ao prazo de validade e às características sensoriais, como cor da gema e da casca. Para os processadores, a qualidade está relacionada também à facilidade de retirar a casca e na separação da gema da clara a às propriedades funcionais (ROSSI; POMPEI, 1995).

A Unidade Haugh (UH), proposta em 1939, é o parâmetro mais usado para expressar a qualidade do albúmen, sendo definida como o logaritmo da altura da clara densa corrigida pela massa do ovo. A escala de Unidade Haugh varia de 20 a 110 e os valores mais frequentes estão entre 50 e 100 (SAUVEUR, 1993). Nos Estados Unidos, a classificação de ovos baseados na Unidade Haugh se dá nos seguintes limites: AA (Firme): UH> 72; A (Razoavelmete firme): UH entre 60 e 72; B (Fraco e aguado): $<60$ - (USDA, 2000).

Visando manter a qualidade interna dos ovos, é de extrema importância o estudo dos fatores que podem contribuir para sua redução no período pós-colheita. A refrigeração não é utilizada no armazenamento e distribuição de ovos no Brasil, principalmente devido ao seu alto custo (XAVIER et al., 2008). Dessa forma, o recobrimento da casca com materiais que limitem a troca gasosa é uma alternativa promissora na melhoria da qualidade de ovos. Diversos trabalhos têm sido publicados avaliando o efeito de recobrimentos biodegradáveis na qualidade de ovos, como proteínas do soro de leite, quitosana, glúten de trigo, zeína de milho, entre outros (WAIMALEONGORA-EK et al., 2009; CANER, 2005; BHALE et al., 2003; WONG; HERALDS; HACHMEISTER, 1996). Entretanto, tais recobrimentos apresentam alto custo e envolvem materiais ou técnicas de difícil acesso na 
própria propriedade para a maioria dos pequenos produtores. Entre materiais de fácil obtenção, Silva et al. (2010a) avaliaram o efeito da utilização da cobertura com fécula de mandioca, mas verificaram que o uso de uma suspensão com $5 \%$ de fécula de mandioca não foi eficiente no retardamento do envelhecimento de ovos. Os autores sugeriram, dessa forma, a realização de mais estudos para a avaliação de tecnologias acessíveis visando manter a qualidade de ovos. Neste sentido, o recobrimento com tintura de própolis pode ser uma alternativa viável para aumentar o tempo de vida de prateleira de ovos.

A própolis é uma substância resinosa produzida por abelhas de vários gêneros com as finalidades de proporcionar isolamento de umidade nas partes internas da colmeia, fixar partes internas, madeiras e favos, proteger a colmeia do desenvolvimento de fungos e alguns tipos de bactérias e proteger a colmeia da entrada de luz (LIMA et al., 2009; AHN et al., 2007). É constituída por polifenóis, quinonas, cumarinas, esteróides, aminoácidos e compostos inorgânicos, sendo que a maioria dos componentes da própolis são de natureza fenólica, principalmente flavonóides. Fenóis simples, ácidos fenólicos e polifenóis são agentes antimicrobianos ativos (COWAN, 1999). Diversos autores tem relatado atividade antimicrobiana da própolis (SEIDEL et al., 2008; TOSI et al., 2007; LU; CHEN; CHOU, 2005), salientando que ela pode variar dependendo da região e de estação, uma vez que é resultado da disponibilidade de matérias primas vegetais (LIBERIO et al., 2009; LU; CHEN; CHOU, 2005).

Assim, o objetivo deste trabalho foi avaliar o efeito da cobertura com própolis de Apis mellifera no aumento do prazo de validade de ovos de galinhas.

\section{Material e Métodos}

O experimento foi montado em um delineamento inteiramente casualizado, em um esquema fatorial $3 \times 5$, sendo três tratamentos pós-colheita (sem lavar, lavado e com própolis) avaliados em cinco tempos $(0,14,30,42$ e 56 dias de armazenamento), com doze repetições.

Os ovos de galinhas foram obtidos de granja com manejo caipira. Os ovos foram divididos ao acaso em três grupos. Para o primeiro grupo, os ovos foram acondicionados sem limpeza e foram denominados "sem lavar" (grupo A). Os ovos do segundo grupo foram lavados com água e, em seguida, foram higienizados com solução de hipoclorito de sódio a $1 \%$ e foram denominados "lavados" (grupo B). No terceiro grupo, os ovos foram lavados com água e higienizados com solução de hipoclorito de sódio a $1 \%$ para depois receberem uma cobertura com extrato alcoólico de própolis, sendo denominados "com própolis" (grupo C). Para aplicação da cobertura, os ovos foram imersos em extrato de própolis por um minuto, sendo depois secos ao ar, em temperatura ambiente.

A própolis utilizada foi proveniente de Apis mellifera L., do tipo marrom, coletada entre os meses de outubro de 2010 e março de 2011 em apiários localizados no sul do Estado do Paraná, com pastagem apícola típica da Floresta ombrófila mista. Após a limpeza, a própolis foi embalada em frascos de polietileno e mantida sob refrigeração à $-4{ }^{\circ} \mathrm{C}$ durante 12 horas. Em seguida, $100 \mathrm{~g}$ do material foi triturado, acondicionado em um recipiente de vidro âmbar e teve o volume completado para um litro com álcool etílico $80^{\circ} \mathrm{GL}$. A mistura foi deixada em repouso durante 5 dias, com agitação manual diária por um minuto. Em seguida, a mistura foi filtrada em filtro de papel e armazenada em local escuro.

Os ovos foram acondicionados à temperatura ambiente sendo periodicamente avaliados quanto à perda de massa, massa específica, unidade Haugh, tamanho da câmara de ar e flotagem em água. As avaliações foram realizadas a cada 14 dias e ao final do experimento os ovos foram também submetidos à análises microbiológicas quanto à presença de bactérias do grupo coliformes totais, incubados a 
$35{ }^{\circ} \mathrm{C}$, dos termófilos, incubados a $45{ }^{\circ} \mathrm{C}$ e quanto à presença de bactérias do gênero Salmonella conforme Silva et al. (2010b).

Para as análises de perda de massa e massa específica, os ovos de cada tratamento tiveram suas massas determinadas ao início do experimento e aos $14,30,42$, e 56 dias de armazenamento. A perda de massa foi calculada subtraindo-se as massas iniciais das massas dos ovos nos dias de avaliação.

A massa específica foi a realizada de acordo com o método descrito por Freitas et al. (2004). A massa específica do ovo foi calculada (equação 1):

$$
M E=\frac{P A}{(P A-P A G) x F C} \quad(\text { equação 1) }
$$

na qual $\mathrm{ME}=$ massa específica; $\mathrm{PA}=$ massa do ovo ao ar; $\mathrm{PAG}=$ massa do ovo na água; e $\mathrm{Fc}=$ fator de correção da densidade em função da temperatura da água.
Aos 14, 30, 42 e 56 dias de armazenamento os ovos de cada tratamento foram colocados em um becker com água para avaliação da flotagem em água. Os ovos que flotaram foram considerados impróprios para consumo e descartados. Ao final do experimento (56 dias de armazenamento), os ovos foram submetidos à análise microbiológica, não restando ovos nos tratamentos "sem lavar" e "lavados" para determinação de unidade Haugh e altura da câmara de ar.

Para acompanhar a qualidade interna pela unidade Haugh (UH), os ovos, após serem pesados em balança semi-analítica, foram quebrados sobre uma superfície plana para medir a altura do albúmen com o uso de um micrômetro, com precisão de 0,01 $\mathrm{mm}$. A medida foi realizada no ponto médio entre a extremidade da gema e a extremidade externa do albúmen mais espessa, evitando-se as chalazas. A unidade Haugh foi calculada segundo Alleoni e Antunes (2001) (equação 2):

$$
U H=100 \log \left[H-\frac{\sqrt{G\left(30 W^{0,37}-100\right)}}{100}+1,9\right] \quad \text { (equação 2) }
$$

na qual: $\mathrm{H}=$ altura da clara espessa (milímetros); $\mathrm{G}=$ constante gravitacional de valor $32 ; \mathrm{W}=$ massa do ovo (gramas).

Para avaliação do tamanho da câmara de ar, os ovos foram cozidos em água fervente por cinco minutos. Após o cozimento, parte da casca foi retirada e a altura da câmara de ar presente no ovo foi medida com o uso de um micrômetro, com precisão de $0,01 \mathrm{~mm}$.

Aos 56 dias de armazenamento, em cinco ovos de cada tratamento foi realizada a avaliação da presença de Salmonella sp., coliformes totais (incubados a $35{ }^{\circ} \mathrm{C}$ ) e coliformes termotolerantes (fecais) incubados a $45{ }^{\circ} \mathrm{C}$ conforme descrito por Silva et al. (2010b).

Os dados obtidos, exceto os de percentagem de flotagem e os dados da avaliação da qualidade microbiológica, foram submetidos aos testes de homogeneidade das variâncias (teste de Bartlett) e normalidade (teste de KomogorovSmirnov). Os dados de perda de massa foram transformados para raiz de $\mathrm{x}$ para cumprir a condição de homocedasticidade. Em seguida, os dados foram submetidos a ANOVA e teste de Tukey para comparação entre os tratamentos qualitativos (lavados, sem lavar e com própolis) e submetidos à análise de regressão para avaliação do comportamento ao longo do tempo de armazenamento utilizando-se os software SAEG 9.1 .

\section{Resultados e Discussão}

Os ovos submetidos aos tratamentos sem lavar, lavado e com própolis e aos períodos de armazenamento pós-colheita apresentaram diferenças significativas para todas as variáveis 
avaliadas.

A percentagem de flotagem dos ovos evoluiu linearmente com o tempo, partindo de $6,5 \%$ (sem lavar), 5,0\% (lavado) e 0,0\% (com própolis), aos 14 dias de armazenamento para 81,8 \% (sem lavar), $73,9 \%$ (lavado) e 7,9\% (com própolis), ao final de 56 dias de armazenamento (Figura 1). A flotagem é um indicador simples da perda de massa específica dos ovos, sendo, portanto, coerente com os dados de massa específica. Todos os grupos apresentaram reduções lineares na massa específica com o decorrer do tempo de armazenamento (Tabela 1). As maiores taxas de redução, porém, ocorreram nos grupos A e B ("sem lavar" e "lavado"), com taxas de $-0,0019$ e $-0,0020 \mathrm{~g} \mathrm{~mL}^{-1} \mathrm{dia}^{-1}$ para os grupos A e $\mathrm{B}$ e de apenas $-0,0010 \mathrm{~g} \mathrm{~mL}^{-1} \mathrm{dia}^{-1}$ para o grupo C (“com própolis"). Ao final do experimento, as massas especificas para os grupos A e B foram, em média, inferiores a $1 \mathrm{~g} \mathrm{~mL}^{-1}$, o que explica a alta percentagem de flotagem para estes grupos (Figura 1).

Figura 1. Percentagem de flotagem para os ovos submetidos aos tratamentos "sem lavar", "lavados" e "com própolis" ao longo do período de armazenamento.

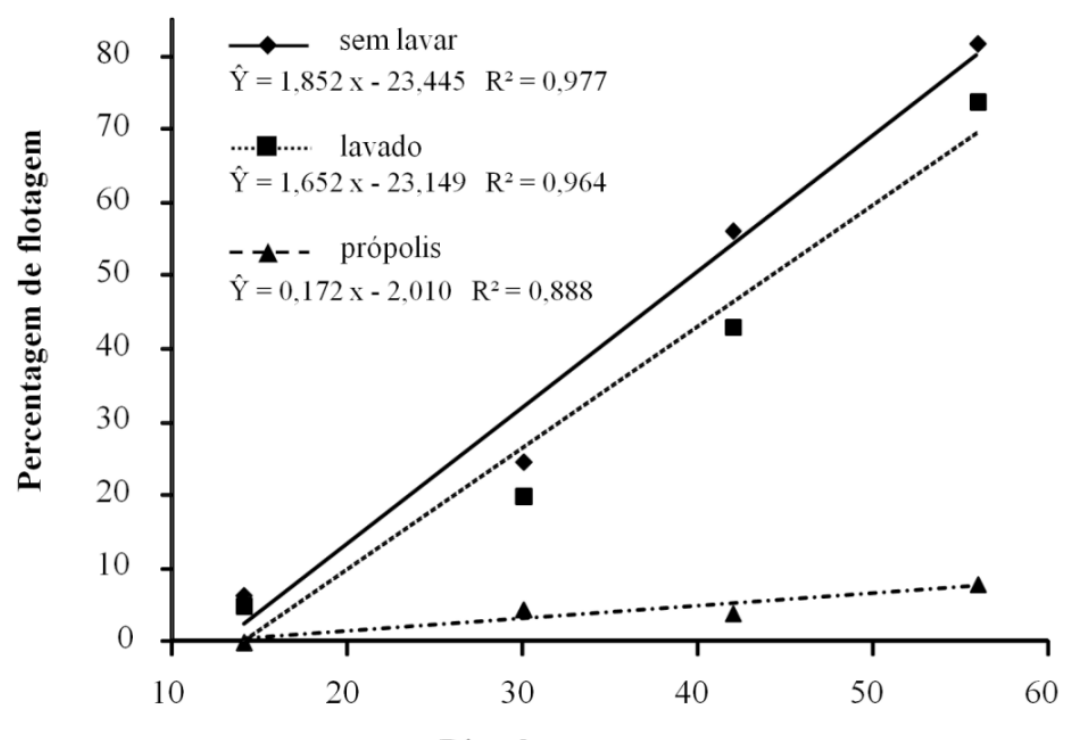

Dias de armazenamento

Fonte: Elaboração dos autores.

Tabela 1. Massa específica $\left(\mathrm{g} \mathrm{mL}^{-1}\right)$ dos ovos submetidos aos tratamentos “sem lavar", "lavados" e "com própolis" ao longo do período de armazenamento.

\begin{tabular}{lccccccc}
\hline \multirow{2}{*}{ Tratamento } & 0 & 14 & 28 & 42 & 56 & Equação & $\mathrm{R}^{2}$ \\
\cline { 2 - 7 } & $1,080 \mathrm{a}$ & $1,072 \mathrm{a}$ & $1,041 \mathrm{~b}$ & $1,019 \mathrm{~b}$ & $0,972 \mathrm{~b}$ & $\mathrm{y}=1,0912-0,0019^{* *} \mathrm{x}$ & 0,947 \\
Sem lavar & $1,067 \mathrm{a}$ & $1,057 \mathrm{a}$ & $1,027 \mathrm{~b}$ & $1,005 \mathrm{~b}$ & $0,960 \mathrm{~b}$ & $\mathrm{y}=1,0723-0,0020^{* *} \mathrm{x}$ & 0,956 \\
Lavado & $1,080 \mathrm{a}$ & $1,079 \mathrm{a}$ & $1,064 \mathrm{a}$ & $1,054 \mathrm{a}$ & $1,021 \mathrm{a}$ & $\mathrm{y}=1,0879-0,0010^{* *} \mathrm{x}$ & 0,876 \\
Com própolis & \multicolumn{7}{c}{2,03} \\
\hline CV $(\%)$
\end{tabular}

Médias seguidas pela mesma letra na coluna não diferem entre si em nível de 5\% de probabilidade pelo teste Tukey. ${ }^{* *}$ Significativo em nível de $1 \%$ de probabilidade pelo teste t.

Fonte: Elaboração dos autores. 
A flotagem em água é a mais simples forma de avaliação da qualidade, sendo uma avaliação determinante e segura para o descarte de ovos. O revestimento com própolis permitiu, portanto, uma menor perda de ovos ao longo dos 56 dias de avaliação. A perda de água que ocorre no ovo depois da postura em consequência da evaporação provoca um aumento progressivo da câmara de ar e, consequentemente, a diminuição da massa específica do ovo. Segundo Sauveur (1993), a redução da massa específica do ovo ocorre de forma linear, estimando-se em torno de 0,0016 unidades por dia, em temperatura ambiente $\left(15\right.$ a $\left.22^{\circ} \mathrm{C}\right)$. No presente estudo, os grupos A e B apresentaram taxas de redução superiores aos estimados por Sauveur (1993), provavelmente devido a maior temperatura média. Entretanto para o grupo C, a taxa de redução observada demonstrou que o revestimento de ovos com própolis reduziu as trocas gasosas, diminuindo a queda dos valores de massa específica.
Santos et al. (2009), avaliando o efeito da temperatura e período de estocagem em ovos, observaram uma diminuição de 0,0019 unidades dia${ }^{1}$ sob temperatura ambiente, resultado semelhante ao encontrado no presente estudo para os ovos não recobertos com própolis. Sob refrigeração, estes autores constataram reduções médias de 0,0018 unidades dia $^{-1}$. A redução da massa específica observada no presente estudo para os ovos recobertos com própolis foi, portanto, inferior à observada por Santos et al. (2009) sob refrigeração.

A perda de massa foi afetada pelo tratamento com própolis e pelo tempo de armazenamento (Tabela 2). Durante o período de armazenamento observou-se uma redução na massa dos ovos dos três grupos, mas esta redução foi mais acentuada para os grupos A e B. Ao final do experimento, a perda média de massa foi de 4,64 g (9,4\%) para o grupo A, 4,67 g (9,89\%) para o grupo B, e 2,42 g $(5,29 \%)$ para o grupo C.

Tabela 2. Perda de massa (g) dos ovos submetidos aos tratamentos "sem lavar", "lavados" e "com própolis" ao longo do período de armazenamento.

\begin{tabular}{lcccccc}
\hline \multirow{2}{*}{ Tratamento } & \multicolumn{7}{c}{ Dias de armazenamento } \\
\cline { 2 - 7 } & 14 & 28 & 42 & 56 & Equação & $\mathrm{R}^{2}$ \\
\hline Sem lavar & $0,385 \mathrm{a}$ & $1,731 \mathrm{a}$ & $2,667 \mathrm{a}$ & $4,644 \mathrm{a}$ & $\sqrt{y}=0,1487+0,0361^{* *} x$ & 0,992 \\
Lavado & $0,443 \mathrm{a}$ & $1,761 \mathrm{a}$ & $2,711 \mathrm{a}$ & $4,669 \mathrm{a}$ & $\sqrt{y}=0,1989+0,0352^{* *} x$ & 0,994 \\
Com própolis & $0,040 \mathrm{~b}$ & $0,658 \mathrm{~b}$ & $1,075 \mathrm{~b}$ & $2,423 \mathrm{~b}$ & $\sqrt{y}=-0,2718+0,0326^{* *} x$ & 0,985 \\
\hline $\mathrm{CV}(\%)$ & \multicolumn{7}{c}{11,33} \\
\hline
\end{tabular}

Médias seguidas pela mesma letra na coluna não diferem entre si em nível de $5 \%$ de probabilidade pelo teste Tukey. Comparação entre médias obtidas após transformação dos dados para raiz de $\mathrm{x}$, devido a heterocedasticidade dos dados iniciais. ${ }^{* *}$ Significativo em nível de $1 \%$ de probabilidade pelo teste $\mathrm{t}$.

Fonte: Elaboração dos autores.

A perda de massa durante o armazenamento ocorre pela perda de água e $\mathrm{CO}_{2}$ para o meio. Esta perda está em função, também, da temperatura ambiente, da umidade relativa e da superfície e porosidade da casca (SAUVEUR, 1993). A aplicação de revestimento sobre o ovo diminui estas trocas gasosas, diminuindo a perda. Caner (2005), avaliando o efeito de cobertura de isolado proteico de soro sobre a vida de prateleira de ovos, observou que a aplicação de proteína de soro na concentração de $18 \%$, após quatro semanas, reduziu a perda de massa em 35,9 \%. Wong, Heralds e Hachmeister (1996), avaliando o efeito de diversas coberturas, observaram redução da perda de massa de 17,1 \% com óleo mineral, $28,8 \%$ com ovoalbumina, $41,4 \%$ com isolado proteico de soja, $62,2 \%$ com 
glúten de trigo e 72,1 \% com zeína de milho após quatro semanas de armazenamento. Bhale et al. (2003) também observaram redução na perda de massa utilizando quitosana de baixa e média massa molecular como revestimento de ovos, entretanto o efeito deixou de existir após cinco semanas do tratamento. Silva et al. (2010a), por outro lado, não observaram redução significativa na perda de massa em ovos revestidos com fécula de mandioca. No presente estudo, após quatro semanas de armazenamento, a cobertura com própolis reduziu em 56,1 \% a perda de massa e em 45,1 \% após oito semanas de armazenamento, mostrando-se mais eficiente na redução da perda de massa que a utilização de isolado proteico de soro, óleo mineral, ovoalbumina, isolado proteico de soja, quitosana e fécula de mandioca.

Barbosa et al. (2008), estudando o efeito da temperatura sobre a qualidade de ovos, observaram uma redução de 60,5\% da perda de massa após cinco semanas sob temperatura controlada. A utilização de revestimento de própolis proporcionou, portanto, um efeito semelhante ao armazenamento sob temperatura controlada, mas sem a utilização da cadeia de frios para armazenamento e transporte.

Aaltura dacâmara deardiferiusignificativamente entre os tratamentos com própolis e os demais a partir do $28^{\circ}$ dia de armazenamento (Tabela 3). A altura da câmara de ar evoluiu linearmente com o tempo para os ovos dos grupos A e B, mas manteve-se praticamente constante para os ovos do grupo C. As diferenças não foram significativas entre os grupos A e B, mas foram significativas entre estes e o grupo C. O aumento da câmara de ar, tal como a redução da massa específica, está inversamente correlacionado a perda de massa do ovo, tanto por perda de água quanto por perdas gasosas (respiração). Dessa forma, o aumento da câmara de ar reforça a tendência observada para as variáveis massa específica e perda de massa, evidenciando a grande capacidade que a cobertura com própolis tem em reduzir as trocas gasosas nos ovos e assim estender a vida de prateleira dos mesmos.

Tabela 3. Altura da câmara de ar (mm) dos ovos submetidos aos tratamentos "sem lavar", "lavado" e "com própolis" ao longo do período de armazenamento.

\begin{tabular}{lcccccc}
\hline \multirow{2}{*}{ Tratamento } & \multicolumn{5}{c}{ Dias de armazenamento } \\
\cline { 2 - 7 } & 0 & 14 & 28 & 42 & Equação & $\mathrm{R}^{2}$ \\
\hline Sem lavar & $4,00 \mathrm{a}$ & $4,00 \mathrm{a}$ & $5,20 \mathrm{a}$ & $7,20 \mathrm{a}$ & $\mathrm{Y}=3,764+0,0019^{* *} \mathrm{x}^{2}$ & 0,978 \\
Lavado & $4,00 \mathrm{a}$ & $4,20 \mathrm{a}$ & $5,20 \mathrm{a}$ & $7,60 \mathrm{a}$ & $\mathrm{Y}=3,796+0,002^{* *} \mathrm{x}^{2}$ & 0,967 \\
Com própolis & $4,00 \mathrm{a}$ & $3,40 \mathrm{a}$ & $3,60 \mathrm{~b}$ & $4,40 \mathrm{~b}$ & $\mathrm{Y}=3,85$ & \\
\hline CV $(\%)$ & \multicolumn{7}{c}{25,14} & \\
\hline
\end{tabular}

Médias seguidas pela mesma letra na coluna não diferem entre si em nível de $5 \%$ de probabilidade pelo teste Tukey. ${ }^{* *}$ Significativo em nível de $1 \%$ de probabilidade pelo teste $\mathrm{t}$.

Fonte: Elaboração dos autores.

O valor da unidade de Haugh (UH) diferiu significativamente entre os tratamentos "com própolis" e os demais e ao longo do período de armazenamento avaliado (Tabela 4). Houve um decréscimo linear significativo nos valores de UH com o aumento do tempo de armazenagem dos ovos (Tabela 4). Este declínio foi menos acentuado no grupo $\mathrm{C}$, que foi revestido com própolis, expressando uma menor perda de qualidade interna destes ovos ao longo do período de armazenamento. Os valores de UH apresentados pelos ovos do grupo C (84,04 no início do período de armazenamento para 71,16 ao final de 42 dias), indicam que os ovos tratados com própolis se mantiveram nas classificações AA e A (USDA, 2000), durante 42 dias de armazenamento. 
Tabela 4. Valores de Unidade Haugh dos ovos submetidos aos tratamentos "sem lavar", "lavado" e "com própolis" ao longo do período de armazenamento.

\begin{tabular}{lcccccc}
\hline \multirow{2}{*}{ Tratamento } & \multicolumn{7}{c}{ Dias de armazenamento } \\
\cline { 2 - 7 } & 0 & 14 & 30 & 42 & Equação & $\mathrm{R}^{2}$ \\
\hline Sem lavar & $84,04 \mathrm{a}$ & $71,26 \mathrm{~b}$ & $65,57 \mathrm{~b}$ & $52,75 \mathrm{~b}$ & $\mathrm{Y}=83,3440-0,6949^{* *} \mathrm{x}$ & 0,965 \\
Lavado & $84,04 \mathrm{a}$ & $73,61 \mathrm{~b}$ & $68,37 \mathrm{~b}$ & $54,12 \mathrm{~b}$ & $\mathrm{Y}=84,2508-0,6313^{* *} \mathrm{x}$ & 0,950 \\
Com própolis & $84,04 \mathrm{a}$ & $79,21 \mathrm{a}$ & $75,32 \mathrm{a}$ & $71,16 \mathrm{a}$ & $\mathrm{Y}=83,8540-0,2987^{* *} \mathrm{x}$ & 0,995 \\
\hline \multicolumn{7}{c}{6,26} \\
\hline
\end{tabular}

Médias seguidas pela mesma letra na coluna não diferem entre si em nível de $5 \%$ de probabilidade pelo teste Tukey. ${ }^{* *}$ Significativo em nível de $1 \%$ de probabilidade pelo teste $\mathrm{t}$.

Fonte: Elaboração dos autores.

Wong, Heralds e Hachmeister (1996), avaliando o efeito de diversas coberturas na qualidade interna de ovos, observaram incrementos de $6,8 \%$ na UH para óleo mineral, 13,3\% para ovoalbumina, 57,7 $\%$ para isolado proteico de soja, $61,4 \%$ para glúten de trigo e $62,3 \%$ para zeína de milho, após quatro semanas de armazenamento, em comparação com o grupo controle. Caner (2005), avaliando o efeito de cobertura de isolado proteico de soro sobre a vida de prateleira de ovos, observou que a aplicação de proteína de soro na concentração de $18 \%$, após quatro semanas, provocou um incremento de $27,4 \%$ na UH, comparados com o controle. Bhale et al. (2003), estudando o efeito de três quitosanas de massas molares diferentes, em duas concentrações, observaram incrementos entre $0,96 \%$ e $37,5 \%$ na UH. Silva et al. (2010a) não observaram diferença significativa na UH em ovos revestidos com fécula de mandioca em comparação com ovos sem revestimento. No presente estudo, após seis semanas de armazenamento, a cobertura com própolis provocou incremento de 34,9\% nos valores de UH, mostrando-se eficiente na manutenção da qualidade interna de ovos. Barbosa et al. (2008), estudando o efeito da temperatura sobre a qualidade de ovos, observaram incrementos na UH variando entre $28,5 \%$ e $64,5 \%$, para diferentes linhagens de poedeiras comerciais, após cinco semanas de armazenamento sob temperatura controlada. Novamente, os dados de UH indicam que a utilização de revestimento com própolis apresentou um efeito semelhante ao armazenamento sob temperatura controlada.

AANVISA, por meio da Resolução n ${ }^{\circ} 12$ de 2 de janeiro de 2001 (BRASIL, 2001), regulamenta os padrões microbiológicos para alimentos e estabelece, para ovos integrais, ausência de Salmonella e valores inferiores a $1 \mathrm{UFC}^{-1}$ para coliformes a $45^{\circ} \mathrm{C}$ na clara, gema e suas misturas. Os valores encontrados para a análise microbiológica dos ovos tratados com própolis (Tabela 5) foram inferiores ao estabelecido na legislação citada, estando o produto apto para ser consumido mesmo após 56 dias de armazenamento. Os tratamentos "lavados" e "sem lavar" também apresentaram ausência de UFC's para Salmonella, entretanto, para coliformes a $45^{\circ} \mathrm{C}$, o tratamento "lavado" apresentou 220 UFC $\mathrm{g}^{-1}$. Os resultados obtidos podem estar ligados à atividade antimicrobiana da própolis, especialmente a antibacteriana, fato já amplamente documentado na literatura (SEIDEL et al., 2008; TOSI et al., 2007; LU; CHEN; CHOU, 2005). 
Tabela 5. Valores de NMP para coliformes incubados a $35^{\circ} \mathrm{C}$, coliformes incubados a $45^{\circ} \mathrm{C}$ e Salmonella sp dos ovos submetidos aos tratamentos "sem lavar", "lavado" e "com própolis" ao longo do período de armazenamento.

\begin{tabular}{lccc}
\hline \multicolumn{1}{r}{ Tratamento } & $\begin{array}{c}\text { Coliformes incubados a } \\
35^{\circ} \mathrm{C}(\mathrm{NMP})\end{array}$ & $\begin{array}{c}\text { Coliformes incubados a } \\
45^{\circ} \mathrm{C}(\mathrm{NMP})\end{array}$ & Salmonella sp \\
\hline Sem lavar & 92 & $<3$ & Ausente em $25 \mathrm{~g}$ \\
Lavado & 220 & 220 & Ausente em $25 \mathrm{~g}$ \\
Com própolis & $<3$ & $<3$ & Ausente em 25 g \\
\hline
\end{tabular}

Fonte: Elaboração dos autores.

Os dados do presente estudo apontam para a necessidade de reavaliação dos critérios atualmente em vigor quanto ao prazo de validade de ovos em função da tecnologia pós-colheita utilizada. A cobertura com própolis permitiu a manutenção das qualidades interna e microbiológica dos ovos em níveis aceitáveis por um período significativamente maior que o atualmente definido como período máximo de vida de prateleira.

\section{Conclusões}

O revestimento de ovos com própolis permite que a qualidade dos mesmos seja mantida em níveis adequados para o consumo por mais de 42 dias de armazenamento em temperatura ambiente, uma vez que mantém valores indicativos de boa qualidade para as variáveis unidade Haugh e massa específica, além de parâmetros microbiológicos compatíveis com a legislação vigente.

\section{Agradecimentos}

À FAPEMIG e ao CNPq pelo apoio financeiro. Ao professor Orestes Cruz Guerreiro, da UNAH, pelas sugestões

\section{Referências}

AHN, M. R.; KUMAZAWA, S.; USUI, Y.; NAKAMURA, J.; MATSUKA, M.; ZHU, F.; NAKAYAMA, T. Antioxidant activity and constituents of propolis collected in various areas of China. Food Chemistry, Barking, v. 101, n. 4, p. 1383-1392, 2007.
ALlEONI, A. C. C.; ANTUNES, A. J. Unidade Haugh como medida da qualidade de ovos de galinha armazenados sob refrigeração. Scientia Agricola, Piracicaba, v. 58, n. 4, p. 681-685, 2001.

AUSTIC, R. E.; NESHEIM, M. C. Poultry production. 13. ed. London: Lea Febiger, 1990. 235 p.

BARBOSA, N. A. A.; SAKOMURA, N. K.; MENDONÇA, M. O.; FREITAS, E. R.; FERNANDES, J. B. K. Qualidade de ovos comerciais provenientes de poedeiras comerciais armazenados sob diferentes tempos e condições de ambientes. ARS Veterinaria, Jaboticabal, v. 24, n. 2, p. 127-133, 2008.

BHALE, S.; NO, H. K.; PRINYAWIWATKUL, W.; FARR, A. J.; NADARAJAH, K.; MEYERS, S. P. Chitosan coating improves shelf life of eggs. Journal of Food Science, Chicago, v. 68, n. 7, p. 2378-2383, sept. 2003.

BRASIL. Ministério da Saúde. Agência Nacional de Vigilância Sanitária - ANVISA. Resolução no 12 , de 02 de janeiro de 2001. Aprova o Regulamento Técnico sobre padrões microbiológicos para alimentos. Diário Oficial [da] República Federativa do Brasil, Brasília, DF, 10 jan. 2001. Disponível em: <http://portal.anvisa.gov.br/wps/ $\mathrm{wcm} / \mathrm{connect} / \mathrm{a} 47 \mathrm{bab} 8047458 \mathrm{~b} 909541 \mathrm{~d} 53 \mathrm{fbc} 4 \mathrm{c} 6735 /$ RDC_12_2001.pdf?MOD=AJPERES >. Acesso em: 12 maio $201 \overline{3}$.

CANER, C. Whey protein isolate coating and concentration effects on egg shelf life. Journal of the Science of Food and Agriculture, New York, v. 85, n. 13, p. 2143-2148, 2005.

COWAN, M. M. Plant products as antimicrobial agents. Clinical Microbiological Review, Washington, v. 12, n. 4, p. 564-582, 1999.

FREITAS, E. R.; SAKOMURA, N. K.; GONZALEZ, M. M.; BARBOSA, N. A. A. Comparação de métodos de determinação da gravidade específica de ovos de poedeiras comerciais. Pesquisa Agropecuária Brasileira, Brasília, v. 39, n. 5, p. 509-512, 2004. 
LIBERIO, S. A.; PEREIRA, A. L. A.; ARAUJO, M. J. A. M.; DUTRA, R. P.; NASCIMENTO, R. F. R.; MONTEIRO-NETO, V.; RIBEIRO, M. N. S.; GONÇALVES, A. G.; GUERRA, R. N. M. The potential use of propolis as a cariostatic agent and its actions on mutans group streptococci. Journal of Ethnopharmacology, Copenhagen, v. 125, n. 1, p. 1- 9, 2009.

LIMA, B.; TAPIA, A.; LUNA, L.; FABANI, M. P.; SCHMEDA-HIRSCHMANN, G.; PODIO, N.; WUNDERLIN, D. A.; FERESIN, G. E. Main flavonoids, DPPH activity, and metal content allow determination of the geographical origin of propolis from the province of San Juan (Argentina). Journal Agricultural and Food Chemistry, Washington, v. 57, n. 7, p. 2691-2698, 2009.

LU, L. C.; CHEN, Y. W.; CHOU, C. C. Antibacterial activity of propolis against Staphylococcus aureus. International Journal of Food Microbiology, Rome, v. 102, n. 2, p. 213- 220, 2005.

ROSSI, M.; POMPEI, C. Changes in some egg components and analytical values due to hen age. Poultry Science, Champaign, v. 74, n. 1, p. 152-160, 1995.

SANTOS, M. S. V.; ESPÍNDOLA, G. B.; LÔBO, R. N. B.; FREITAS. E. R.; GUERRA, J. L. L.; SANTOS, A. B.

E. Efeito da temperatura e estocagem em ovos. Ciência e Tecnologia de Alimentos, Campinas, v. 29, n. 3, p. 513517, 2009.

SAUVEUR, B. El huevo para consumo: bases productivas. Barcelona: Aedos Editorial, 1993. 377 p.

SEIDEL, V.; PEYFOON, E.; WATSON, D. G.; FEARNLEY, J. Comparative study of the antibacterial activity of propolis from different geographical and climatic zones. Phytotherapy Research, Malden, v. 22, n. 9, p. 1256-1263, 2008.
SILVA, A. L. S.; BROLEZE, L. F.; SIDOU, L. F.; HENRIQUES, C. Y. H.; SPANOL, T. M.; AUGUSTO, P. E. D. Qualidade de ovos recobertos com fécula de mandioca. Tecnologia \& Ciência Agropecuária, João Pessoa, v. 4, n. 3, p. 43-46, 2010a.

SILVA, N.; JUNQUEIRA, V. C. A.; SILVEIRA, N. F. A.; TANIWAKI, M. H.; SANTOS, R. F. S.; GOMES, R. A. R. Manual de métodos e análise microbiológica de alimentos e água. 4. ed. São Paulo: Livraria Varela, 2010b. 625 p.

TOSI, E. A.; RÉ, E.; ORTEGA, M. E.; CAZZOLI, A. F. Food preservative based on propolis: bacteriostatic activity of propolis polyphenols and flavonoids upon Escherichia coli. Food Chemistry, Barking, v. 104, n. 3, p. 1025-1029, 2007.

USDA. United States Department of Agriculture. AMS 56 - United States Standards, Grades, and Weight Classes for Shell Eggs, 2000. Disponível em: $<$ http://www.ams.usda. gov/AMSv1.0/getfile?dDocName=STELDEV3004376 >. Acesso em: 12 maio 2013.

WAIMALEONGORA-EK, P.; GARCIA, K. M.; NO, H. K.; PRINYAWIWATKUL, W.; INGRAM, D. R. Selected quality and shelf life of eggs coated with mineral oil with different viscosities. Journal of Food Science, Chicago, v. 74, n. 9, p. S423-S429, 2009.

WONG, Y. C.; HERALDS, T. J.; HACHMEISTER, K. A. Evaluation of mechanical and barrier properties of protein coatings on shell eggs. Poultry Science, Savoy, v. 75, n. 3, p. 417-422, 1996.

XAVIER, I. M. C.; CANÇADO, S. V.; FIGUERERO, T. C.; LARA, L. J. C.; LANA, A. M. Q.; SOUZA, M. R.; BAIÃO, N. C. Qualidade de ovos de consumo submetidos a diferentes condições de armazenamento. Arquivos Brasileiros de Medicina Veterinária e Zootecnia, Belo Horizonte, v. 60, n. 4, p. 953-959, 2008. 